\title{
Bone-targeted Agents Used in Breast Cancer Patients with Bone Metastases
}

\author{
Başak OYAN
}

Department of Internal Medicine, Section of Medical Oncology, Acıbadem University, Acıbadem Altunizade Hospital, Istanbul-Turkey

\section{Introduction}

Bone is the most common site of metastases in breast cancer. Bone metastasis develops in $73 \%$ of the patients with metastatic breast cancer.[1] Bone metastases cause skeletal complications in $68 \%$ of the patients with breast cancer including, pathological fractures in 52\%, need for radiotherapy in $43 \%$, surgery requirement in $11 \%$, and spinal cord compression in 3\% of patients.[2] Skeletal-related events (SRE) develop early in the course of the disease. The median time to first SRE is 7 months in breast cancer patients with bone metastases.[2]

Bisphosphonates effectively reduce skeletal complications. On comparing pamidronate for up to 2 years with placebo in breast cancer patients with at least one lytic bone metastasis, the former was observed to reduce the rate of SREs from $68 \%$ to $53 \%$.[2] Zoledronic acid reduced SRE risk by an additional $20 \%$ compared to pamidronate.[3] On comparing oral ibandronate with zoledronic acid, the former failed to achieve noninferiority in reducing the risk of SRE.[4]

Denosumab is a monoclonal antibody against RANKL and inhibits bone resorption. Denosumab has been evaluated for SRE prevention in three large, international, randomized, double-blind phase III trials in patients with bone metastases. In all these trials, patients in the control arm received zoledronic acid. One of these trials was specific to patients with breast cancer. [5] Patients were randomized to denosumab $120 \mathrm{mg}$ subcutaneous (SC) and placebo intravenous (IV) every four weeks or zoledronic acid $4 \mathrm{mg}$ IV and placebo SC Q4W. Denosumab was superior to zoledronic acid in delaying time to first and subsequent SREs.

The adherence to guidelines for bone health in cancer is suboptimal. Despite the proven efficacy of bone- targeted agents in bone metastases of solid malignancies, including breast cancer, $20-50 \%$ of the patients with bone metastases do not receive any of these agents to prevent SREs. [6-8]

Recommendations for the use of bone-targeted agents in breast cancer patients with bone metastases as per the European Society for Medical Oncology practice guidelines are as follows: [9]

- All breast cancer patients with bone metastases, even when asymptomatic, should receive zoledronate or denosumab.

- Zoledronic acid and denosumab are both effective. The choice of the agent depends on the efficacy, patient's preferences, renal functions, and cost.

- Denosumab is superior to zoledronic acid in terms of efficacy. Also, it is administered as an SC injection, while zoledronic acid is administered as an IV infusion.

- Three monthly dosing intervals of zoledronic acid are non-inferior to monthly dosing and have become a standard approach in patients with breast cancer.[10,11] The less frequent dosing regimen of zoledronic acid can be more preferable for some patients. Denosumab is administered every four weeks. Currently, it is not recommended to extend intervals.

- Denosumab is the agent of choice for patients with impaired renal functions.

- Oral ibandronate is an alternative for patients who desire to receive oral therapy.

- Treatment with bone-targeted agents should be continued as long as it is beneficial for the patient. However, selected patients with oligometastatic disease can discontinue therapy if they have a low risk
Accessible online at: www.onkder.org

OPEN ACCESS This work is licensed under a Creative Commons Attribution-NonCommercial 4.0 International License.
Dr. Başak OYAN

Acıbadem Üniversitesi,

Acıbadem Altunizade Hastanesi,

İç Hastalıkları Anabilim Dalı,

Tıbbi Onkoloji Bölümü,

Istanbul-Turkey

E-mail: basak.uluc@acibadem.com 
of bone complications or when there is a long period of disease remission.

- All patients should have a dental evaluation before initiation of bisphosphonates and denosumab. All invasive dental procedures should be completed before initiating bone-targeted agents to prevent jaw osteonecrosis.

- Vitamin D supplementation with adequate calcium intake is recommended.

- Renal functions should be monitored in patients receiving zoledronic acid.

\section{References}

1. Coleman RE. Clinical features of metastatic bone disease and risk of skeletal morbidity. Clin Cancer Res 2006;12(20 Pt 2):6243s-6249s.

2. Lipton A, Theriault RL, Hortobagyi GN, Simeone J, Knight RD, Mellars $\mathrm{K}$, et al. Pamidronate prevents skeletal complications and is effective palliative treatment in women with breast carcinoma and osteolytic bone metastases: long term follow-up of two randomized, placebo-controlled trials. Cancer 2000;88(5):1082-90.

3. Rosen LS, Gordon D, Kaminski M, Howell A, Belch A, Mackey J, et al. Long-term efficacy and safety of zoledronic acid compared with pamidronate disodium in the treatment of skeletal complications in patients with advanced multiple myeloma or breast carcinoma: a randomized, double-blind, multicenter, comparative trial. Cancer 2003;98(8):1735-44.

4. Barrett-Lee P, Casbard A, Abraham J, Hood K, Coleman R, Simmonds P, et al. Oral ibandronic acid versus intravenous zoledronic acid in treatment of bone metastases from breast cancer: a randomised, open label, non-inferiority phase 3 trial. Lancet Oncol 2014;15(1):114-22.

5. Stopeck AT, Lipton A, Body JJ, Steger GG, Tonkin K, de Boer RH, et al. Denosumab compared with zoledronic acid for the treatment of bone metastases in patients with advanced breast cancer: a randomized, double-blind study. J Clin Oncol 2010;28(35):5132-9.

6. Oster G, Lamerato L, Glass AG, Richert-Boe KE, Lopez A, Chung K, et al. Use of intravenous bisphosphonates in patients with breast, lung, or prostate cancer and metastases to bone: a 15-year study in two large US health systems. Support Care Cancer 2014;22(5):1363-73.

7. Trinkaus M, Simmons C, Myers J, Dranatisaris G, Clemons M. Skeletal-related events (SREs) in breast cancer patients with bone metastases treated in the nontrial setting. Support Care Cancer 2010;18(2):197-203.

8. Mortimer JE, Schulman K, Kohles JD. Patterns of bisphosphonate use in the United States in the treatment of metastatic bone disease. Clin Breast Cancer 2007;7(9):682-9.

9. Coleman R, Hadji P, Body JJ, Santini D, Chow E, Terpos E, et al. Bone health in cancer: ESMO Clinical Practice Guidelines. Ann Oncol 2020;31(12):1650-63.

10. Amadori D, Aglietta M, Alessi B, Gianni L, Ibrahim T, Farina G, et al. Efficacy and safety of 12-weekly versus 4-weekly zoledronic acid for prolonged treatment of patients with bone metastases from breast cancer (ZOOM): a phase 3, open-label, randomised, non-inferiority trial. Lancet Oncol 2013;14(7):663-70.

11. Hortobagyi GN, Van Poznak C, Harker WG, Gradishar WJ, Chew H, Dakhil SR, et al. Continued treatment effect of zoledronic acid dosing every 12 vs 4 weeks in women with breast cancer metastatic to bone: The OPTIMIZE-2 randomized clinical trial. JAMA Oncol 2017;3(7):906-12. 